\title{
Total and occupationally active life expectancies in relation to social class and marital status in men classified as healthy at 20 in Finland
}

\author{
Jaakko Kaprio, Seppo Sarna, Mikael Fogelholm, Markku Koskenvuo
}

\begin{abstract}
Study objective - To study differences in total life expectancy and in occupationally active life expectancy in relation to social class and marital status in men classified as healthy as young adults.

Design - Historical cohort study.

Setting - Finland.

Participants - Altogether 1662 men classified as completely healthy at the time of induction to military service (mean birth year 1923), who had been selected as referents for a study of former athletes. Mean follow up time was 46 years.

Measurements - Vital status was determined by follow up through local parish data up to 1990 . Mortality data were obtained from the Cause of Death bureau of the Central Statistical Office of Finland. Occurrence of work disability was assessed from nationwide disability pension register data. Mean total life expectancy and mean occupationally active life expectancy (end points disability pension or death before age 65 years) were estimated. Social class was based on the major lifetime occupation, while marital status was classified as "never married" or "ever married" at the end of follow up.
\end{abstract}

Main results - Mean total life expectancy was highest among executives and managers ( 73.2 (95\% confidence interval (CI): 70.3,76.1) years), next highest in clerical (white collar) workers $\mathbf{( 7 2 . 0} \mathbf{( 7 0 . 0 , 7 4 . 1 )}$ years), and lowest in unskilled blue collar workers $(63.65(61.1,66.2)$ years). Skilled workers and farmers were intermediate. For the occupationally active life expectancy estimates, a similar gradient was observed: highest for executives (61.9 $(60.7,63.1)$ years) and lowest for the unskilled (52.2 (50.2,54.2) years). The ratio of occupationally active life expectancy to total life expectancy was highest for executives (85\%) and lowest for farmers $(81 \%)$ and unskilled workers $(82 \%)$.

Conclusions - The social class gradient known to exist for mortality is also present for occupational disability. Social class and marital status differences in mortality are already evident in early adulthood and continue into old age. Those with the highest life expectancy also have the largest proportion of their life span free of occupationally incapacitating disability.

(f Epidemiol Community Health 1996;50:653-660)
While the mean life expectancy has increased considerably in most populations during this century with a reduction in premature mortality, total life span has not increased correspondingly during the past decades. ${ }^{1}$ There has been debate over whether increases in mean life expectancy are accompanied by decreases in morbidity (that is, is there compression of morbidity?) ${ }^{1}$ or longer periods of disability and dependency. ${ }^{23}$ These alternative scenarios differ greatly in their implications for the development of health care costs as populations age.

In addition to mortality data, a fuller picture of the state of national health can be obtained by using other measures based on morbidity, disability, and lifestyle data. The healthy life expectancy measure ${ }^{3}$ is a composite index for evaluating change in population health that is computed from institutionalisation rates and prevalence data on activity restrictions compared with mortality rates. In a review of published work using this measure of disability free life expectancy, Robine and Ritchie found gender, age, and socioeconomic group were associated with this composite index. ${ }^{3}$ In Canada, the richest fifth of the population both lived longer and had a proportionately greater disability free life compared with the poorest fifth. ${ }^{4}$ Studies of disability have focused mostly on the elderly. A recent study of the elderly in the United States suggests that the more educated have a longer disability free life expectancy, but the proportion of remaining years of life estimated to be disability free did not vary in relation to gender or education. ${ }^{5}$ However, more longitudinal research is necessary to examine whether chronic functional limitation in terms of time is actually compressed in more advantaged population groups over the entire life span. ${ }^{6}$

Differences among adults in health outcome in relation to socioeconomic status may be due to factors operating in adult life or generational effects transmitted from parents to children. There is a continuing debate over the relative role of recent effects versus long term effects in creating health inequalities. ${ }^{7-10}$ In this paper we have attempted to study the effects of socioeconomic status in adults by examining subjects who were classified as healthy as young adults. We examined both mortality and morbidity in a cohort of Finnish men born in the early part of this century and classified as healthy at the age of 20 . We used as a measure of morbidity the occurrence of premature retirement on a disability pension and computed estimates of total 
and occupationally active life expectancy. The relationship of morbidity to mortality in terms of social class and marital status is also studied.

\section{Methods}

DEFINITION OF STUDY COHORT

The subjects were selected from those Finnish men who at the age of 20 had been classified as completely healthy (class $\mathrm{AI}$, fully fit for ordinary military service) at the medical examination for induction into military service, which is compulsory for all Finnish men. These subjects were originally chosen to be referents for a study of mortality in former top male athletes. ${ }^{11}$ The subjects were selected from the register of men liable for military service; these listings for the period in the present study are archived by the Finnish Defence Forces. The subjects were in the same age cohort and area of residence as the athletes, and the selection of each referent was done after first finding the athlete in the register. The AI conscript listed nearest was then chosen as the referent. The group comprised 1712 men. ${ }^{11}$

After finding their personal data, and with permission from the local authorities, the subjects were traced mainly through records of residence in local parish registers. In Finland, there is a long tradition of population registration going back three to four centuries. Thus local parishes have recorded all births, deaths, marriages, and migration from and to the local parish. In the next phase personal identification codes (a unique 11 character code assigned to each Finnish citizen in the 1960s) were obtained from the parish records. The personal identification code permits accurate computerised record linkage to other registries. Data on profession, marital status, and vital status were collected from the Central Population Registry (CPR) of Finland with permission from the appropriate authority. The CPR was formed in the late 1960 s as a computerised data bank of Finnish citizens based on the data in the local parish records. Vital status was recorded as of December 1990. Vital status was unknown for 50 men and so the sample size for the survival analyses was 1662 men.

CLASSIFICATION OF SOCIAL CLASS AND MARITAL STATUS

Some of the data on social class and marital status were collected from the CPR and the rest from the 1985 questionnaire study described below. Classification by social class was based on the 4-digit code of occupation in official use in Finland. ${ }^{1213}$ Each person was classified according to the occupation in which he had spent most time during his life. In this study, occupations were grouped into the following social classes: executives, clerical workers, skilled workers, unskilled workers, and farmers. People in long term care facilities, retired people of unknown occupation, and students were not classified in relation to social class and were considered as missing data. Marital status was missing in $2.2 \%(\mathrm{n}=36)$ of subjects and social class was missing for $9.0 \%(n=149)$. The number of subjects in relation to social class and marital status is given in the left-hand columns of tables 1 and 4 . The men were classified as single, ie, they had never married or as ever married (married, divorced, or widowed) because the dates of marriage, divorce, or widowhood were not recorded during data collection. Social class and marital status were strongly associated $\left(\chi^{2}\right.$ test $\left.p<0.001\right)$, for example, $35 \%$ of single men were unskilled workers compared with $8.3 \%$ of those ever married.

In 1985, a questionnaire study was carried out to obtain historical data mainly for follow up studies of the former athletes and referents. ${ }^{11}$ It was mailed to surviving subjects who were alive on January 1, $1985(\mathrm{n}=1099,66.1 \%$ of the original subjects). The items of the questionnaire contained data on sociodemographic factors (including marital status and occupation) as well as physical attributes, psychological traits, lifestyle factors, and medical history. The response rate was $81 \%$. These cross sectional data on other risk factors cannot be directly used in the analyses here as the corresponding data on those who died before 1985 are not available.

\section{MORTALITY AND MORBIDITY DATA}

Copies of death certificates were obtained for the years 1936-89 using the files of the Cause of Death Bureau at the Central Statistical Office of Finland. Ten men (0.6\%) died before 1936. While no cause of death could be reliably established for them as medical certification of death became obligatory only in 1936, their date of death was recorded. For subjects who died after death certification had become obligatory, cause of death was missing for 32 ( $1.9 \%$ of all subjects); most of these men had died outside Finland. The underlying cause of death was recorded using the International Classification of Diseases (ICD-8). Conversion from other ICD versions to the version 8 codes was done by the authors. When estimating life expectancies, those 61 men (3.7\% of the total) who died in combat during World War II were accounted for by placing them into the "lost" category in survival analyses. We did this because we considered determinants of war deaths to be different from determinants of violent deaths in peacetime.

Disability pension data was obtained from the Social Insurance Institute of Finland. Disability pension under age 65 years can be granted in Finland when a subject's work capacity is reduced by at least $40 \%$ according to an expert review of occupational and medical data. ${ }^{14}$ Record linkage using the personal identification number yielded data on new disability pensions granted between January 1, 1970 and July 30,1989 . For subjects alive in 1970 , information on disability pensions granted before 1970 was also available. Cause of disability was classified according to the diagnoses (at most three) given in the medical certificate and recorded in the pensions register. Cause specific analyses were done using all subjects with the selected diagnosis irrespective of the presence 


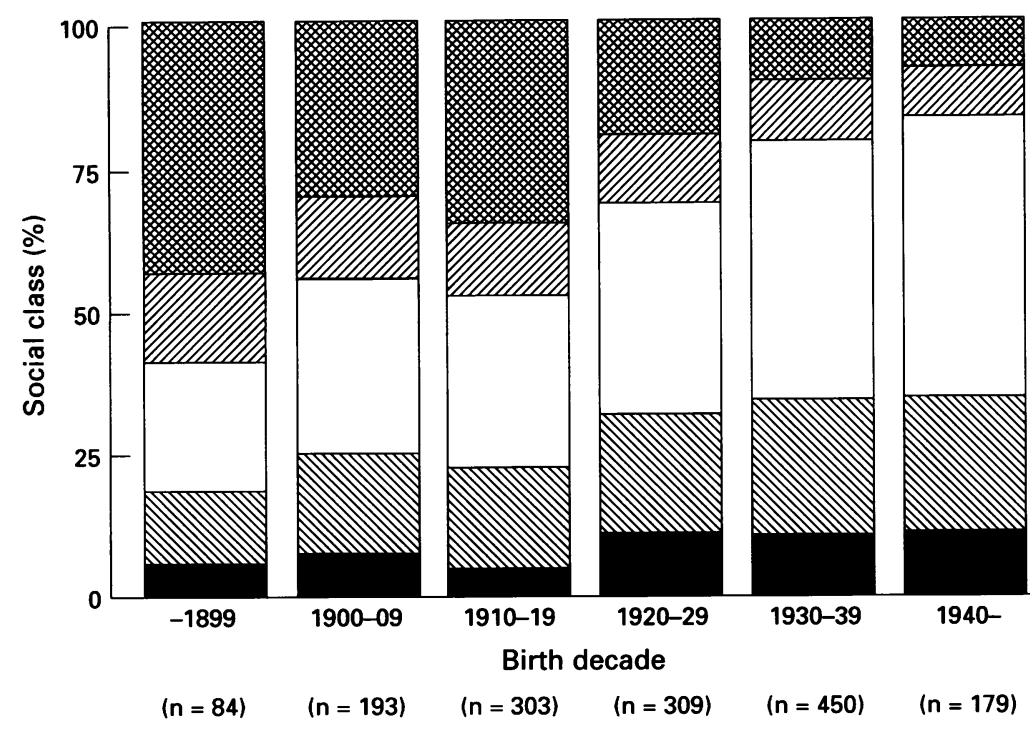

Professionals Clerical $\square$ Skilled $\square$ Unskilled Farmers

Figure 1 Distribution of subjects in relation to social class in each birth decade.

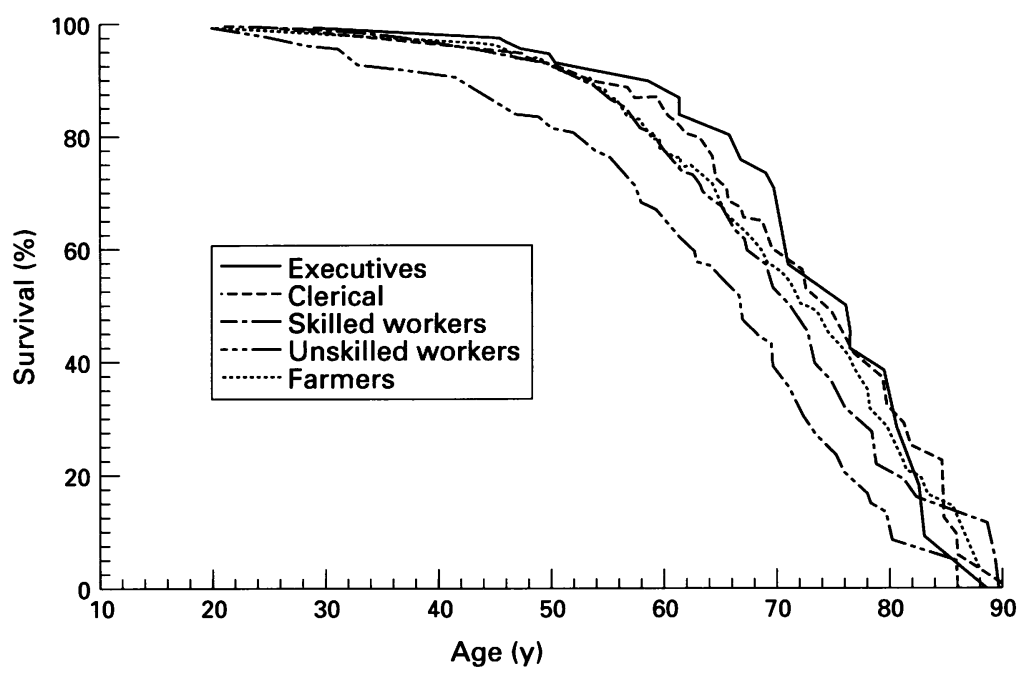

Figure 2 All cause mortality in relation to social class in men classified as completely healthy at induction examination for military service and followed up to December 1989. Stratified Kaplan-Meier product-limit method was used.

or absence of other diagnoses on the certificate. The date of granting the pension was recorded to the nearest month. In cases where a temporary pension had been granted first and then followed by a permanent pension, the date of first award was used. A total of 338 subjects (76 pensions granted before 1970) had retired early on disability pension. The main medical causes of disability were cardiovascular disease, musculoskeletal disease, and mental illness.

\section{STATISTICAL ANALYSIS}

The statistical analyses of survival data ${ }^{15}$ were done with $B M D P$ statistical software programs $1 \mathrm{~L}$ and $2 \mathrm{~L} .{ }^{16}$ Estimates of life expectancy were calculated using the stratified Kaplan-Meierproduct limit method (1L). For the total mortality analysis, follow up time was from the time of entry to the study (ie, 20 years old, the age at conscription) until death or the end of follow up. Those alive after follow up were treated as censored observations. In the morbidity analysis, the end of follow up was defined as retirement on disability pension or death before age 65 , while subjects who reached the age of 65 or the end of follow up on December 31, 1989 were censored. The life expectancy estimate from the disability analysis is called an occupationally active life expectancy, that is an estimate of the average age at which the capacity to work ends. If no events occur, the occupationally active life expectancy would be 65 years, which is normal retirement age. Strata were formed by social class and marital status (single versus ever married). Breslow's test ${ }^{17}$ was used to evaluate the differences between the survival curves. The test places more weight on deaths at younger ages.

Estimates for morbidity and mortality hazard ratios were calculated using Cox's proportional hazards model (BMDP $2 L$ ) to permit adjustment of covariates (marital status and social class). Four dummy variables for social class were constructed in the model with "clericals" as the reference category. The event of interest in the morbidity analyses was retirement on disability pension, while subjects who reached the age of 65 years, or who were alive at the end of follow up on December 31, 1989 were censored. Confidence intervals for the HR were computed from the model parameter estimates and their standard errors using the following formula:

$$
C I=\exp (\text { beta } \pm 1.96(\text { SE(beta })),
$$

where beta is the parameter specific regression coefficient. Analyses were also done for main diagnostic categories.

\section{Results}

The mean birth year for all subjects was 1923 , with follow up from age 20 years, which is the average age of military service. The birth years of the subjects ranged from 1884-1946, with $70.1 \%$ of subjects born between 1910 and 1939. Unskilled workers and farmers were over represented in the earlier birth decades (fig 1). However, a Cox regression analysis of total mortality in relation to birth decade indicated that after adjustment for social class, mortality by birth decade did not vary significantly. Compared with men born before 1900, the adjusted mortality hazards ratios were: 1.20 (95\% confidence interval $0.92,1.57$ ) for men born in $1900-9,1.13(0.86,1.49)$ for men born 1910$19,1.17(0.86,1.59)$ for men born 1920-29, $0.91(0.63,1.31)$ for men born $1930-39$, and $1.04(0.56,1.95)$ for men born after 1940. Therefore decade of birth was not considered as a confounder in the analyses.

\section{SOCIAL CLASS DIFFERENCES}

The survival curves for total mortality (fig 2) in relation to social class differed significantly from each other $(p<0.0001)$. The curve for unskilled workers is less rectangular than for 
Table 1 Mean occupationally active and total life expectancy estimates (95\% confidence intervals) at the age of 20, and the ratio of occupationally active life expectancy (OALE) to total life expectancy (TLE) in relation to social class in Finnish men followed up until 1989

\begin{tabular}{llll}
\hline Social class (no) & $\begin{array}{l}\text { Occupationally active } \\
\text { life expectancy }\end{array}$ & Total life expectancy & $\begin{array}{l}\text { OALE/TLE } \\
\text { (\%) }\end{array}$ \\
\hline Executives (127) & $61.91(60.7,63.1)$ & $73.19(70.3,76.1)$ & 84.6 \\
Clericals (314) & $59.77(58.8,60.7)$ & $72.01(70.0,74.1)$ & 83.0 \\
Skilled workers (578) & $58.31(57.5,59.1)$ & $69.78(68.2,71.4)$ & 83.6 \\
Unskilled workers (177) & $52.17(50.2,54.2)$ & $63.65(61.1,66.2)$ & 82.0 \\
Farmers (317) & $57.08(55.8,58.4)$ & $70.78(69.0,72.5)$ & 80.6 \\
\hline
\end{tabular}

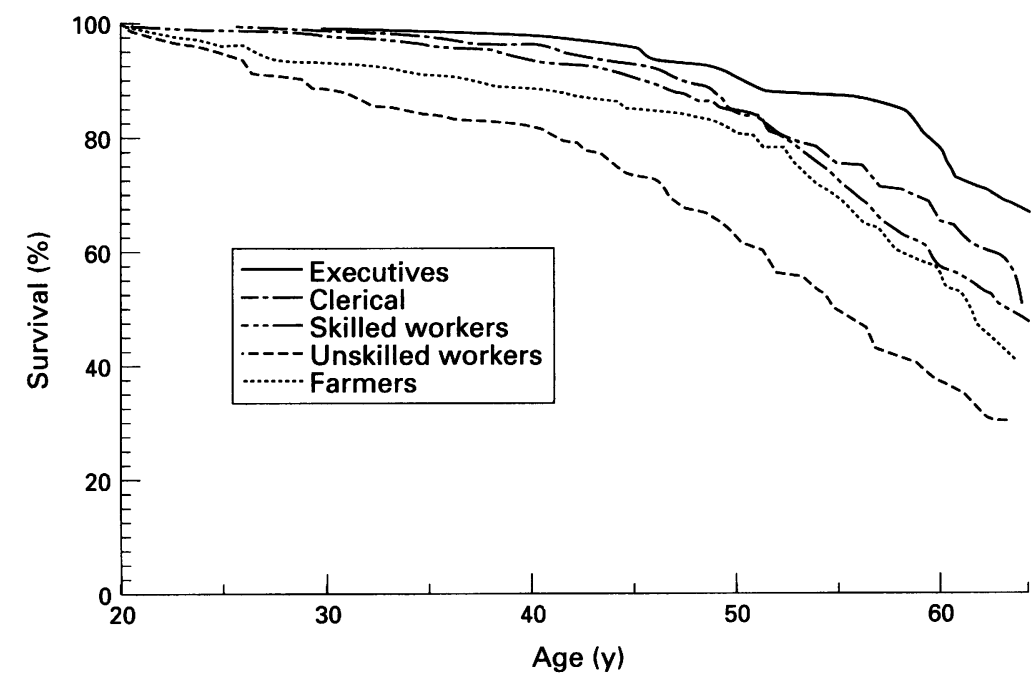

Figure 3 Occupational disability from all causes before the age of 65 years in relation to social class in men classified as completely healthy at induction examination for military service and followed up until 30 fune 1989. Stratified Kaplan-Meier product-limit method was used.

Table 2 All cause and cause specific* mortality hazard ratios (HR), their $95 \%$ confidence intervals (95\% CI), number of events, and p values (likelihood ratio test) in relation to social class in Finnish men followed up until 1989. Cox regression analysis: $H R$ in relation to social class adjusted for marital status

\begin{tabular}{|c|c|c|c|c|}
\hline Social class & Cancer & $\begin{array}{l}\text { Cardiovascular } \\
\text { disease }\end{array}$ & $\begin{array}{l}\text { Violent } \\
\text { causes }\end{array}$ & All \\
\hline \multicolumn{5}{|l|}{ Executives } \\
\hline HR & 1.25 & 1.28 & 1.15 & 1.03 \\
\hline $95 \%$ CI & $0.56,2.81$ & $0.75,2.19$ & $0.37,3.54$ & $0.71,1.49$ \\
\hline No of events & & & & 36 \\
\hline p & 0.59 & 0.38 & 0.81 & 0.88 \\
\hline \multicolumn{5}{|c|}{ Clerical workers (reference } \\
\hline HR & 1.00 & 1.00 & 1.00 & 1.00 \\
\hline No of events & 22 & 45 & 10 & 100 \\
\hline \multicolumn{5}{|l|}{ Skilled workers } \\
\hline HR & 2.09 & 1.84 & 1.25 & 1.58 \\
\hline $95 \% \mathrm{CI}$ & $1.26,3.47$ & $1.29,2.61$ & $0.60,2.63$ & $1.26,1.99$ \\
\hline No of events & 47 & 88 & 17 & 196 \\
\hline$p$ & 0.0034 & 0.0005 & 0.55 & $<0.0001$ \\
\hline \multicolumn{5}{|c|}{ Unskilled workers } \\
\hline HR & 2.69 & 2.84 & 3.28 & 2.37 \\
\hline $95 \% \mathrm{CI}$ & $1.47,4.92$ & $1.91,4.23$ & $1.52,7.06$ & $1.82,3.09$ \\
\hline No of events & & 47 & 14 & 98 \\
\hline p & 0.0018 & $<0.0001$ & 0.003 & $<0.0001$ \\
\hline \multicolumn{5}{|l|}{ Farmers } \\
\hline $\mathrm{HR}$ & 1.60 & 1.69 & 0.84 & 1.36 \\
\hline $95 \%$ CI & $0.94,2.72$ & $1.19,2.41$ & $0.35,2.04$ & $1.07,1.71$ \\
\hline No of events & 34 & 81 & 8 & 159 \\
\hline $\mathrm{p}$ & 0.082 & 0.003 & 0.70 & 0.011 \\
\hline
\end{tabular}

* Classification of causes by ICD-8 rubrics: cancer 140-209, cardiovascular disease 390-438, and violent causes $800-999$.
The survival curves for occupational disability (fig 3 ) in relation to social class also differed significantly from each other $(\mathrm{p}<0.0001)$. The mean occupationally active life expectancy was highest for executives (61.9 $(95 \%$ CI $60.7,63.1)$ years) and lowest for unskilled workers $(52.2(50.2,54.2)$ years). Clerical workers, skilled workers, and farmers had intermediate estimates of occupationally active life expectancy (table 1). The ratio of occupationally active life expectancy to total life expectancy was highest for the executives $(85 \%)$ and lowest for the unskilled workers $(82 \%)$ and farmers $(81 \%)$.

The total mortality HR in relation to social class compared with the mortality of the clerical workers were based on the Cox model. After adjustment for marital status, significantly raised $\mathrm{HR}$ were observed for farmers ( $\mathrm{HR}=$ 1.36), skilled workers ( $H R=1.58)$, and unskilled workers ( $\mathrm{HR}=2.37$ ) (table 2$)$. $\mathrm{HR}$ in relation to the cause of death category were high in unskilled workers for cancer $(\mathrm{HR}=$ $2.69)$, cardiovascular disease $(\mathrm{HR}=2.84)$ and violent causes $(H R=3.28)$. Skilled workers had a significantly increased risk of cancer ( $\mathrm{HR}=$ 2.09) and of cardiovascular disease ( $H R=$ 1.84). For farmers only the cardiovascular mortality risk was significantly increased $(\mathrm{HR}=$ 1.69).

The Cox model was also used to obtain total disability HR in relation to social class (table 3 ). After adjustment for marital status, significantly high HR were observed for skilled workers $(\mathrm{HR}=1.60)$ and for unskilled workers $(\mathrm{HR}=$ 2.34). Skilled workers had a significantly increased HR for musculoskeletal disorders $(\mathrm{HR}=2.16)$, while unskilled workers had significantly increased risks for psychiatric disorders $(\mathrm{HR}=2.76)$ and musculoskeletal disorders $(\mathrm{HR}=3.44)$.

DIFFERENCES IN RELATION TO MARITAL STATUS Significant differences $(p<0.0001)$ in survival were observed in relation to marital status (fig 4). Single men had a much shorter total life expectancy (65.6 years) compared with the ever married men (71.4 years) (table 4 ). The survival curves for occupational disability in relation to marital status (fig 5) differed significantly $(p<0.0001)$. For occupationally active life expectancy, the pattern in relation to marital status was similar to the mortality results. Single men had the shortest occupationally active life expectancy (49.8 years), while ever married men (59.4 years) had the longest occupationally active life expectancy (table 4) and the ratio of occupationally active life expectancy to total life expectancy was much lower for single men than men who had ever been married.

The analysis by Cox's proportional hazards models estimated the total and cause specific mortality HR of single men compared with the ever married men after adjustment for social class (table 5). Significantly high HR were observed for single men for all causes of death $(\mathrm{HR}=1.11)$ as well as for cardiovascular disease $(H R=1.11)$. The Cox model was also 
Table 3 All cause and cause specific* disability hazard ratios (HR), their $95 \%$ confidence intervals (95\% CI), number of events, and p values (likelihood ratio test) in relation to social class in Finnish men aged 20 at baseline and followed up until 1989. Cox regression analysis: HR in relation to social class adjusted for marital status

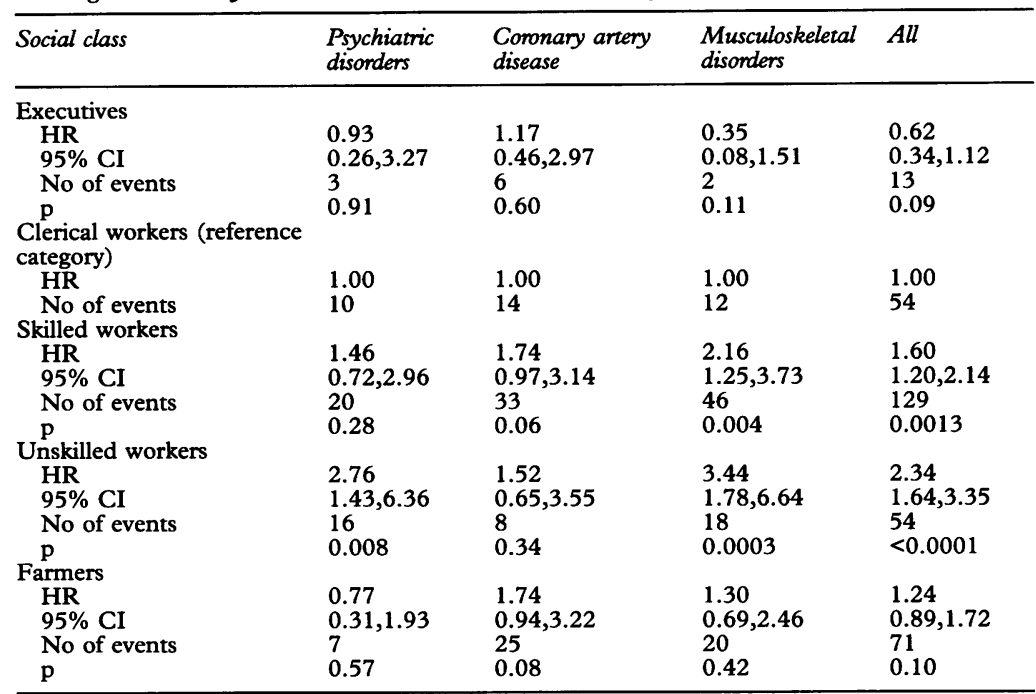

* Classification of causes by ICD-9 rubrics: psychiatric disorders 290-319, coronary artery diseas $410-414$, and musculoskeletal disorders $710-739$.

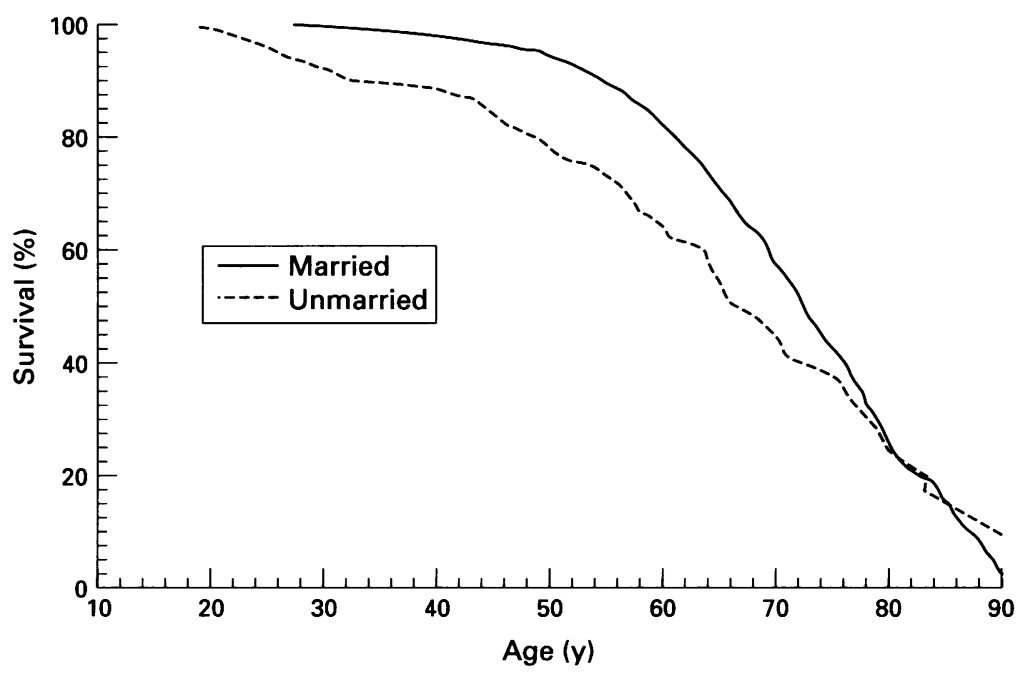

Figure 4 Mortality from all causes in relation to marital status for single men and ever married men (married, divorced, widowed) classified as completely healthy at induction examination for military service and followed up until December 1989. The stratified Kaplan-Meier product-limit method was used.

Table 4 Mean occupationally active and total life expectancy estimates at the age of 20, their $95 \%$ confidence intervals (95\% CI), and the ratio of occupationally active life expectancy (OALE) to total life expectancy (TLE) in relation to marital status in Finnish men aged 20 at baseline followed up until 1989

\begin{tabular}{llll}
\hline $\begin{array}{l}\text { Marital status } \\
\text { (no) }\end{array}$ & $\begin{array}{l}\text { Occupationally active } \\
\text { life expectancy }\end{array}$ & $\begin{array}{l}\text { Total life } \\
\text { expectancy }\end{array}$ & $\begin{array}{l}\text { OALE/TLE } \\
\text { (\%) }\end{array}$ \\
\hline Single (227) & $49.82(47.8,51.9)$ & $65.59(62.35,68.83)$ & 76.0 \\
Ever married (1399) & $59.42(59.0,59.9)$ & $71.36(70.47,72.25)$ & 83.3 \\
\hline
\end{tabular}

used to obtain the total and cause specific disability HR for single men compared with married men (table 6). After adjustment for social class, significantly high HR were observed for all causes of disability $(H R=1.40)$ and for disability due to psychiatric disorders $(\mathrm{HR}=4.49)$ - based on a total of 46 cases in single men, 22 of whom were "disabled" because of psychiatric disorders.

\section{Discussion}

Inequality of health in relation to socioeconomic status persists in European countries. ${ }^{1819}$ These inequalities have also persisted in Finland, ${ }^{2021}$ despite programmes over the past decades to reduce differences between the more affluent and the poor. The present cohort analysis suggests that social class and marital status differences in mortality and morbidity are already evident in young adults and that these differences persist throughout nearly the entire life span. The difference in mean life expectancy between the most advantaged (executives and managers) and least advantaged (unskilled workers) groups was over nine years. Differences in morbidity in relation to socioeconomic status are well documented ${ }^{1022-24}$ as are differences in mortality.$^{13212526}$ In different countries cross sectional and short term cohort studies have also confirmed differences in morbidity and mortality in relation to socioeconomic status. ${ }^{2027-32}$ Epidemiological studies with a long follow up are fewer, and many have initially studied middle aged men, such as the seven countries cohorts, ${ }^{33}$ or selected population groups. The Framingham study has studied men and women aged 30 and over and found educational attainment to be a powerful predictor of risk and mortality. ${ }^{34-36}$ Similarly, a Dutch study of 78505 men aged 18 years at baseline found that education level predicted mortality over a follow up period of 32 years. ${ }^{37}$ Differences in mortality risk from coronary heart disease, cancer, and accidents in relation to educational level were very similar in these men, who were aged 50 years at the end of follow up. ${ }^{37}$

Health status in pregnancy, infancy, and childhood also varies in relation to socioeconomic status. Prenatal and childhood factors have been shown to predict cardiovascular risk and mortality in adults, ${ }^{38-43}$ though the early studies have been criticised for not adjusting adequately for persisting socioeconomic differences. ${ }^{44}$ Ecological analyses ${ }^{45}$ based on mortality data from England and Wales suggested that the direct effects on mortality of deprivation in childhood are probably weak.

In the present study, the subjects were healthy at the time of their compulsory military service, because they had been classified as free of any disease or injury (class AI). In the induction medical examinations between 1964 and $1970,68 \%$ to $75 \%$ of men in any one year were classified as A-I. The proportion decreased after that (range $48-66 \%$ ) up to 1987 , as more men had minor diagnoses mentioned (class AII, fully fit for military service but with minor health problems such as spectacles) (Finnish Defence Forces Medical Service personal communication). While precise statistics from earlier years were not available, we may reasonably conclude that the men in the present study were selected because they were completely healthy at age 20 . Thus, social class differences in adult mortality were found after excluding manifest childhood morbidity. In a Dutch study of 18 year old men followed up to age 50 , health status at age 18 and height did not lessen the predictive power of education. ${ }^{37}$ 


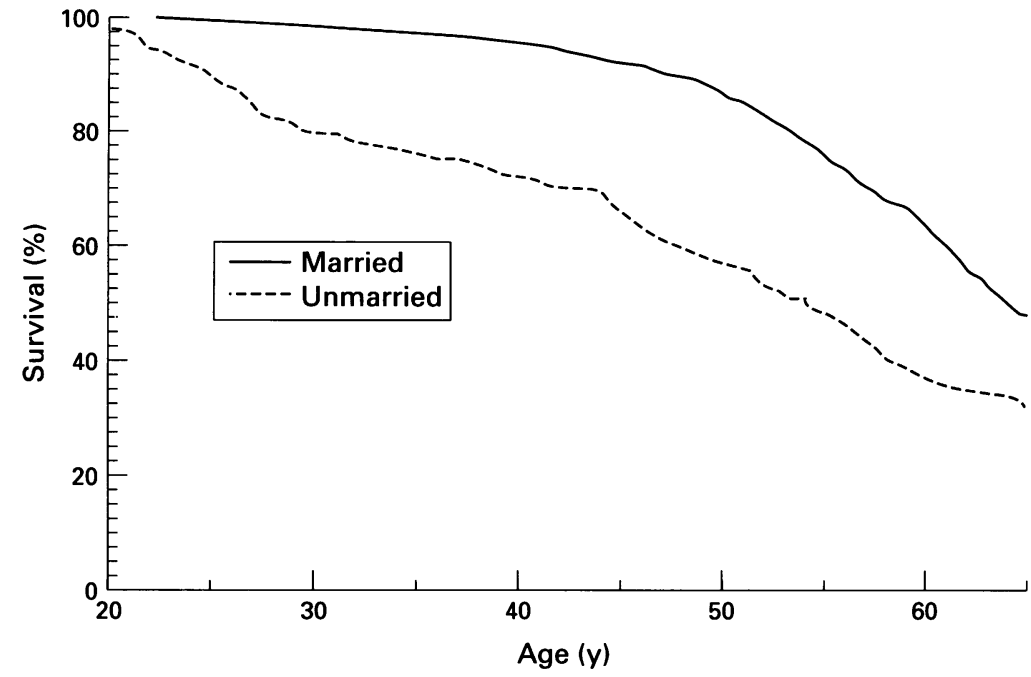

Figure 5 Occupational disability from all causes before age 65 years in relation to marital status for single men and ever married men (married, divorced, widowed) classified as completely healthy at induction examination for military service and followed up until fune 1989. The stratified Kaplan-Meier product-limit method was used.

Table 5 All cause and cause specific* mortality hazard ratios (HR), their 95\% confidence intervals (95\% CI), number of events, and $p$ values (likelihood ratio test) in relation to marital status. Cox regression analysis: marital status $H R$ adjusted for social class

\begin{tabular}{lllll}
\hline Marital status & Cancer & $\begin{array}{l}\text { Cardiovascular } \\
\text { disease }\end{array}$ & $\begin{array}{l}\text { Violent } \\
\text { causes }\end{array}$ & All \\
\hline Unmarried & 1.10 & 1.11 & & \\
$\quad$ HR & $0.98,1.25$ & $1.03,1.20$ & 0.21 & 1.11 \\
$\quad$ 95\% CI & 16 & 33 & 20 & $1.05,1.17$ \\
$\quad$ No of events & 0.08 & 0.007 & 0.052 & 92 \\
$\quad$ p & 1.00 & 1.00 & 1.0001 & \\
$\begin{array}{l}\text { Ever married (reference } \\
\text { category) }\end{array}$ & 116 & 252 & 36 & 1.00 \\
$\quad$ HR & No of events & & 525 \\
\hline
\end{tabular}

* Classification of causes by ICD-8 rubrics: cancer 140-209, cardiovascular diseases $390-438$, and violent causes $800-999$.

Table 6 All cause and cause specific* disability hazard ratios (HR), their 95\% confidence intervals (95\% CI), number of events, and p values (likelihood ratio test) in relation to marital status. Cox regression analysis: marital status adjusted for social class

\begin{tabular}{lllll}
\hline Marital status & $\begin{array}{l}\text { Psychiatric } \\
\text { disorders }\end{array}$ & $\begin{array}{l}\text { Cononary artery } \\
\text { disease }\end{array}$ & $\begin{array}{l}\text { Musculoskeletal } \\
\text { disonders }\end{array}$ & All \\
\hline Unmarried & & & & \\
$\quad$ HR & 4.49 & 1.22 & 0.63 & 1.40 \\
95\% CI & $2.56,7.87$ & $0.60,2.46$ & $0.29,1.38$ & $1.01,1.93$ \\
$\quad \begin{array}{l}\text { No of events } \\
\text { p }\end{array}$ & 22 & 9 & 7 & 46 \\
$\begin{array}{l}\text { Ever married (reference } \\
\text { category) }\end{array}$ & $<0.0001$ & 0.59 & 0.22 & 0.048 \\
$\quad$ HR & 1.00 & 1.00 & & \\
$\quad$ No of events & 37 & 80 & 1.00 & 1.00 \\
\hline
\end{tabular}

* Classification of causes by ICD-9 rubrics: psychiatric disorders 290-319, coronary artery disease 410-414, and musculoskeletal disorders 710-739.

However, it cannot be concluded that prenatal and childhood factors have been fully controlled for by our study design, for it is possible that the relevant factors influencing adult health do not affect the health of children. Apart from selection for health, our sample seems representative of men born early this century in Finland. The geographical distribution of the places of residence did not differ from that of the general Finnish population. Vital status and cause of death data could be obtained in nearly all subjects despite a long follow up time, so that no strong selection bias has occurred because of loss to follow up.
There are several measures of morbidity, which makes intra- and international comparisons difficult. ${ }^{46}$ Nonetheless, Blaxter's review suggests that differences in morbidity in relation to socioeconomic status are more apparent in chronic conditions than in acute episodes of illness and disability. ${ }^{46}$ The measure of morbidity in this study was premature retirement due to a medically certified disability which reduced capacity to work. In Finland, earnings related pensions are granted by private insurance companies that administer pension funds for private employers and the self employed, and by the public sector pension funds. The Social Insurance Institution grants basic pensions for those aged 16-64 years who are outside the workforce. The database used in the present study covers the entire working age population, because the Social Insurance Institution collates data on all new disability pensions. The measure of morbidity used in the present study indicates that work capacity was lowered due to disease, but it is not a comprehensive measure of disease occurrence.

The present study found significant variation for both social class and marital status in total life expectancy and occupationally active life expectancy. In addition, the patterns of mortality and occupational disability in relation to social class were similar. The unskilled worker group was the most disadvantaged; the total morbidity and mortality HR ratios were both greater than 2.3 compared to the reference category. Those in the executive and managerial groups fared best, though there were no significant differences compared with the clerical workers. Apart from cardiovascular disease, the main diagnoses associated with mortality differed from those associated with work incapacity. With regard to the latter, psychiatric disorders and musculoskeletal diseases were the most common after cardiovascular disease. The pattern of cardiovascular morbidity (disability pensions) in relation to social class was quite similar to the mortality gradient. This is consistent with data on the incidence of coronary artery disease in relation to social class. ${ }^{303147}$ The proportion of total life expectancy that was free of work disability was highest among the executives and lowest in the unskilled workers and farmers. Thus, the social class with highest total life expectancy also had a proportionately higher occupationally active life expectancy. It seems that within this cohort of initially healthy men there is compression of morbidity in the men who fare best, and that social class is a significant predictor of occupationally active life expectancy in addition to its known predictive value for total life expectancy.

Variation in mortality and morbidity in relation to marital status is substantial in Finland ${ }^{4748}$ as in other countries. ${ }^{49-51}$ In this study we have compared single men to all men who have ever married, while many studies have compared married men to all men not married at the time of the study. As data on the date of marriage were not collected, exact person-years in relation to marital status could not be computed. Because the men were clas- 
sified by final marital status, some single men may have died before they had the chance to marry, possibly contributing to the raised mortality risk of single men. However, the mortality rates are at their lowest at age 20-30 years for adult men, and most Finnish men marry by age 30 . The unmarried men had an all causes mortality $\mathrm{HR}$ adjusted for social class of 1.11 , which is the same that Ben-Shlomo et $a l^{49}$ report for single Whitehall civil servants adjusted for age, grade, and height. In their study, single men had a greater risk of accidental death than in the present study. This may be because our reference category included men who subsequently divorced or became widowers; the latter have an increased mortality from violent causes. ${ }^{5253}$ Morbidity was $40 \%$ higher for the single men compared with the ever married in the present study and most of this excess risk was due to psychiatric disorders $(\mathrm{HR}=4.5)$. In our study design whether being single increases psychiatric morbidity, or vice versa, or whether both states have common antecedents cannot be determined. However, men with serious psychiatric disorders at age 20 would not have been included in the study sample.

A limitation of our study is that it does not include data on lifestyle factors or other risk indicators for disease and death. This is due to the design of this historical cohort study, and we cannot therefore determine the extent to which the observed differences in morbidity and mortality in relation to social class and marital status are due to known differences in risk indicators. As discussed by Ben-Shlomo et $a{ }^{49}$ the relationship between risk indicators such as smoking or relative weight and socioeconomic factors is complex. Simple statistical adjustment for a presumed confounder, such as smoking, may underestimate the effect attributable to socioeconomic factors, because some of the effects of social factors on health in later life may be transmitted through lifestyle effects. Because lifestyle factors change over time, longitudinal studies measuring social factors, lifestyle, and other determinants of disease on multiple occasions would be needed to determine better how socioeconomic status and marital status determine health outcomes. Feinstein, in his recent review, ${ }^{10}$ indicated the need for a study linking life span experiences to health care use and the incidence of disease. As well characterised cohorts, such as the British national child development study 1958 cohort ${ }^{9}$ or the northern Finnish 1966 birth cohort study, ${ }^{54}$ become middle aged and older, more information on the timing and nature of social factors affecting variation in health will become available.

1 Fries JF. Aging, natural death, and the compression of morbidity. N Engl F Med 1980;303:130-5.

2 Schneider EL, Brody JA. Aging, natural death, and the compression of morbidity: another view. $N$ Engl f Med 1983;309:854-6.

3 Robine JM, Ritchie K. Healthy life expectancy: evaluation of global indicator of change in population health. $B M F$ 1991;302:457-60.

4 Wilkins R, Adams OB. Health expectancy in Canada, late 1970s: demographic, regional, and social dimensions. $A m$ 1970s: demographic, regional, and

5 Guralnik JM, Land KC, Blazer D, Fillenbaum GG, Branch LG. Educational status and active life expectancy among older blacks and whites. $N$ Engl f Med 1993;329:110-16. 6 House JS, Kessler RC, Herzog AR, Mero RP, Kinney AM, Breslow MJ. Age, socioeconomic status, and health. Milbank $O$ 1990;68:383-411.

7 Illsley R, Baker D. Contextual variations in the meaning of health inequality. Soc Sci Med 1991;32:359-65.

8 Vagerö D. Inequality in health - some theoretical and empirical problems. Soc Sci Med 1991;32:367-71

9 Power C. Social and economic background and class in equalities in health among young adult. Soc Sci Med 1991 32:411-17.

10 Feinstein JS. The relationship between socioeconomic status and health - a review of the literature. Milbank $Q 1993$; 71:279-322.

11 Sarna S, Sahi T, Koskenvuo M, Kaprio J. Increased life expectancy of world class male athletes. Med Sci Sports Exerc 1993;25:237-44.

12 Central Statistical Office. Alphabetical list of occupations and classification of social class. (In Finnish). Helsinki: Central Statistical Office of Finland, 1972

13 Koskenvuo M, Sarna S, Kaprio J, Lönnqvist J. Causespecific mortality by marital status and social class in Finland during 1969-1971. Soc Sci Med 1979;13A:691-7.

14 Rissanen A, Heliövaara M, Knekt P, Reunanen A, Aroma A, Maatela J. Risk of disability and mortality due to overweight in a Finnish population. BMF 1990;301:835-7. Kalbfleisch JD, Prentice RL. The statistical analysis of fail Dixon WJ. BMDP statistical software manual. Berkeley: University of California Press, 1990.

7 Breslow N. A generalized Kruskall-Wallis test for comparing $\mathrm{k}$ samples subject to unequal patterns of censorship. Bik samples subject to unequa

18 Morris JN. Inequalities in health: ten years and little further on. Lancet 1990;336:491-3.

19 Fox J, ed. Health inequalities in European countries. Aldershot: Gower, 1989.

20 Notkola VJ, Martikainen P, Leino PI. Time trends in mortality in forestry and construction workers in Finland 1970-85 and impact of adjustment for socioeconomic variables. 7 Epidemiol Community Health 1993;47:186-91.

21 Valkonen T. Problems in the measurement and international comparisons of socio-economic differences in mortality. Soc Sci Med 1993;36:409-18.

22 Antonovsky A. Social class, life expectancy and overall mortality. Milbank Mem Fund $O$ 1967;45:31-73.

23 Syme SL, Berkman LF. Social class, susceptibility and sickness. Am f Epidemiol 1976;104:1-8.

24 Marmot MG, Kogevinas M, Elston MA. Social/economic status and disease. Annu Rev Public Health 1987;8:111-35.

25 Registrar General. Decennial supplement for England and Wales 1970-72. Occupational mortality. London: HMSO, 1978.

26 Näyhä S. Social group and mortality in Finland. Br 7 Prev Soc Med 1977;31:231-7.

27 Leclerc A, Pietri F, Boitel L, Chastang JF, Carval P, Blondet $M$. Level of education, lifestyle, and morbidity in two groups of white collar workers. 7 Epidemiol Community groups of white collar

28 Marmot MG, Smith GD, Stansfeld S, et al. Health inequalities among British civil servants: the Whitehall II equalities among British civil ser.

29 Hein HO, Suadicani P, Gyntelberg F. Ischaemic heart disease incidence by social class and form of smoking - the Copenhagen male study - 17 years follow-up. F Intern Med 1992;231:477-83.

30 Rosengren A, Wedel H, Wilhelmsen L. Coronary heart disease and mortality in middle aged men from different occupational classes in Sweden. BMF 1988;297:1497-500.

31 Woodward M, Shewry MC, Smith WC, Tunstall-Pedoe H Social status and coronary heart disease: results from the
Scottish heart health study. Prev Med 1992;21:136-48.

32 Nyboe J, Jensen G, Appleyard M, Schnohr P. Risk factors for acute myocardial infarction in Copenhagen. I: Hereditary, acute myocardial infarction in Copenhagen. I: Hereditary, heart study. Eur Heart $f$ 1989;10:910-16.

33 Keys A. Seven countries: a multivariate analysis of death and coronary heart disease. Cambridge, Massachusetts: Harvard University Press, 1980.

34 Eaker ED, Pinsky J, Castelli WP. Myocardial infarction and coronary death among women - psychosocial predictors from a 20-year follow-up of women in the Framingham study. Am J Epidemiol 1992;135:854-64.

35 Garrison RJ, Gold RS, Wilson PW, Kannel WB. Educationa attainment and coronary heart disease risk: the Framattainment and coronary heart disease risk: the

36 Haynes SG, Feinleib M, Kannel WB. The relationship of psychosocial factors to coronary heart disease in the Framingham study. III. Eight-year incidence of coronary heart disease. Am $\mathcal{f}$ Epidemiol 1980;111:37-58.

37 Doornbos G, Kromhout D. Educational level and mortality in a 32-year follow-up study of 18-year old men in the Netherlands. Int $\mathcal{F}$ Epidemiol 1990;19:374-9.

38 Arnesen E, Forsdahl A. The Tromso heart study: coronary risk factors and their association with living conditions during childhood. $f$ Epidemiol Community Health 1985;39. 210-14.

39 Forsdahl A. Living conditions in childhood and subsequen development of risk factors for arteriosclerotic heart disease. The cardiovascular survey in Finnmark 1974-75. $\mathcal{f}$ Epidemiol Community Health 1978;32:34-7.

40 Barker DJ, Hales CN, Fall CH, Osmond C, Phipps K, Clark PM. Type 2 (non-insulin dependent) diabetes mellitus, hypertension and hyperlipidaemia (syndrome $\mathrm{X}$ ): relation to reduced fetal growth. Diabetologia 1993;36:62-7. 
41 Kaplan GA, Salonen JT. Socioeconomic conditions in childhood and ischaemic heart disease during middle age $B M F$ 1990;301:1121-3.

42 Barker DJP, Martyn CN. The maternal and fetal origins of cardiovascular disease. $\mathcal{F}$ Epidemiol Community Health 1992;46:8-11.

43 Barker DJ, Osmond C, Simmonds SI, Wield GA. The relation of small head circumference and thinness at birth to death from cardiovascular disease in adult life. $B M \mathcal{F}$ 1993;306:422-6.

44 Elford J, Whincup P, Shaper AG. Early life experience and adult cardiovascular disease: longitudinal and case-contro studies. Int $\mathcal{F}$ Epidemiol 1991;20:833-44.

45 Ben-Shlomo Y, Smith GD. Deprivation in infancy or in adult life: which is more important for mortality risk? Lancet 1991;337:530-4

46 Blaxter $M$. A comparison of measures of inequality in morbidity. In: Fox J, ed. Health inequalities in Eurpean countries. Aldershot: Gower, 1989:199-230.

47 Koskenvuo M, Kaprio J, Romo $M$, Langinvainio $H$. Incidence and prognosis of ischaemic heart disease with respect to marital status and social class. A national record linkage study. $¥$ Epidemiol Community Health 1981;35: linkage
48 Koskenvuo M, Sarna S, Kaprio J. Mortality by marital status and social class in Finland during 1969-1971. Mortality from natural and violent causes. Scand $\mathcal{F}$ Soc Med 1978; 6:137-43.

49 Ben-Shlomo Y, Smith GD, Shipley M, Marmot MG. Magnitude and causes of mortality differences between married and unmarried men. $\mathcal{F}$ Epidemiol Community Health 1993; 47:200-5.

50 Mendes de Leon CF, Appels AWPM, Otten FWI, Schouten EGW. Risk of mortality and coronary heart disease by EGW. Risk of mortality and coronary heart disease by marital status in middle-aged

51 Malcolm JA, Dobson AJ. Marriage is associated with a lower risk of ischaemic heart disease in men. Med $\mathcal{F}$ Aust 1989; 151:185-8.

52 Kaprio J, Koskenvuo M, Rita H. Mortality after bereavement: a prospective study of 95,647 widowed persons. Am $\mathcal{F}$ Public Health 1987;77:283-7.

53 Helsing KJ, Comstock GW, Szklo M. Causes of death in a widowed population. Am f Epidemiol 1982;116:524-32.

54 Isohanni M, Oja $\mathrm{H}$, Moilanen I, Rantakallio P, Koiranen $M$. The relation between teenage smoking and drinking, with special reference to non-standard family background. with special reference to non-standar 